\title{
Effects of Expression Technology on Physical Parameters and Phytochemical Profile of Echinacea purpurea Juice
}

\author{
Ernesto A. Brovelli \\ Concentrate Development, Nutrilite - A Division of Access Business Group \\ $196006^{\text {th }}$ Street, Lakeview, CA 92567-403
}

\begin{abstract}
Alain Y. Boucher and John T. Arnason
Department of Biology, University of Ottawa, 30 Marie Curie, Ottawa, ON, K1N 6N5, Canada
\end{abstract}

\section{Gopi R. Menon and Rodney M. Johnson \\ Concentrate Development, Nutrilite-A Division of Access Business Group $196006^{\text {th }}$ Street, Lakeview, CA 92567-403}

Additional index words. purple coneflower, juice, cichoric acid, alkylamides, press technology becomes an increasingly important concern in the herbal market (Awang, 2000), the focus of processing technology evaluations should be placed on the stability of marker and active compounds thereby conserving therapeutic value, all the while keeping in mind production efficiency and engineering considerations. Very little to date has been published to address the question of quality differences in Echinacea preparations due to postharvest factors. Most of the presently available information deals with effects of drying on the important constituents of Echinacea preparations (Kim et al., 2000; Perry et al., 1999) and does not specifically describe the impact of the different technologies used in processing.

The following experiment was conducted as a comparative assessment between two commonly used juice extraction technologies, a hydraulic bag press and a Reitz screw press. This assessment was based on physical and phytochemical parameters measured from the E. purpurea juices extracted by the two types of press.

\section{Materials and Methods}

Plant material and pressing, E. purpurea was grown from seed at an Access Business Group certified organic farm located in Lakeview, Calif. During Spring 2000, the aerial parts of E. purpurea were field-mowed and chopped to $\approx 1 / 4$ inch using an Urschel mill. Six lots of material were segregated and blanched independently in a steam blancher at $100{ }^{\circ} \mathrm{C}$ for $3 \mathrm{~min}$. The material reached a minimum of $82.2^{\circ} \mathrm{C}$ before being discharged from the blancher via a screw conveyer. Afterblanching, three lots of the material were pressed using a hydraulic bag press (Good Nature Products, Buffalo, N.Y.) and three lots were pressed using a Reitz screw press (Bepex, Minneapolis). Samples were collected for the following determinations: cichoric acid concentration, alkylamide fraction profile, total solids, soluble solids, color, viscosity, and $\mathrm{pH}$. Each sample was analyzed for its chemical composition immediately following pressing.

Cichoric acid HPLC analyses. Twelve samples were prepared for each press type by mixing $1 \mathrm{~mL}$ of juice and $1 \mathrm{~mL}$ of methanol. After shaking, samples were filtered using a $1-\mu \mathrm{m}$ glass fiber filter and $0.2-\mu \mathrm{m}$ polyvinylidene filter. Ten microliters of the sample were injected in a Hewlett Packard 1100 model HPLC (Palo Alto, Calif.). Separation was done on a Nova-Pack C18 3.9-mm $\times$ 300-mm column at room temperature with a constant flow rate of $1 \mathrm{~mL} / \mathrm{min}$. The initial mobile phase consisted of $20 \%$ Acetonitrile (solvent A) and $80 \% 0.4 \% \mathrm{H}_{3} \mathrm{PO}_{4} / \mathrm{H}_{2} \mathrm{O}$ (solvent B). A linear gradient was applied over $10 \mathrm{~min}$, increasing solvent A to $35 \%$. Cichoric acid was detected with a Photodiode Array Detector set at a wavelength of $320 \mathrm{~nm}$. An HPLC grade cichoric acid standard, purchased from Apin Chemicals, product \#15486C (Abingdon, Oxon, U.K.) was used for identification and quantification of samples.

Alkylamide thin-layer chromatography $(T L C)$ profile. Pressed juice samples of 5
Received for publication 26 Sept. 2002. Accepted for publication 25 Apr. 2003. 
$\mathrm{mL}$ were extracted with $4 \mathrm{~mL}$ of $\mathrm{CHCl}_{3}$ and centrifuged. The $\mathrm{CHCl}_{3}$ layer was separated and the sample was dried over anhydrous $\mathrm{Na}_{2} \mathrm{SO}_{4}$. Alltech (Nicholasville, Ky.) HPTLC silica gel 60 GF254 plates were used with a 7 hexane : 3 ethyl acetate mobile phase. Volumes of $80 \mu$ Lwere spotted along an 8 -mm-wide line. Alkylamides were detected by spraying anisaldehyde reagent $(0.5 \%$ anisaldehyde with $10 \mathrm{~mL}$ of glacial acetic acid in methanol, heated at $105^{\circ} \mathrm{C}$ ). The alkylamides appear as purple in color. The major alkylamides found in the aerial parts of E. purpurea belong to 2,4-diene structure type. The most abundant are 2E,4E,8Z,10E-dodeca-tetraenoic acid isobutylamide and 2E,4E,8Z,10Z-dodecatetraenoic acid isobutylamide (Fig. 1). Both of these compounds have an $\mathrm{Rf}$ value of 0.33 under the TLC conditions described above. In order to confirm the identification of alkylamides in the separated bands, these were collected individually from TLC plates, washed with $\mathrm{MeOH}$ and analyzed with HPLC/MS to determine molecular mass and separation patterns. Due to the unavailability of commercial standards at the time of this study, quantitative evaluation was not possible. In light of this, TLC analysis was chosen as a reliable, semiquantitative and faster alternative to HPLC analysis (Wagner and Bladt, 1996).

Physical parameters. Total solids were assessed by measuring loss of mass after drying liquids for $4 \mathrm{~h}$ at $80^{\circ} \mathrm{C}$. Soluble solids were determined by a PR-101 Atago digital refractometer (Atago U.S.A., Kirkland, Wash.). Color (spectral reflectance) was determined using a top-port Minolta CM 3500-d spectrophotometer (Minolta, Osaka, Japan), which was calibrated using as references the black and white tiles provided by the manufacturer. The juice viscosity was evaluated with a Brookfield Digital Viscometer, model LVTDV-II (Brookfield Engineering Laboratories, Stoughton, Mass.). This provides an objective measure of juice consistency by measuring the torque required to rotate a specified cylinder immersed in the juice at specified rotational rates. All of the above physical parameters were measured on twelve samples for each of the press types.

Statistical analysis. Independent two group $t$ tests were conducted for the following measured variables: $\mathrm{pH}$, viscosity, density, solids (total and soluble), and cichoric acid concentration. The analyses were carried out using Systat (standard vers. 9.01) statistics software. Differences in means were considered statistically significant when $P$ values were $<0.05$.

\section{Results and Discussion}

Levels of soluble solids and of total solids was used to characterize the juices obtained with the different presses. In our study, no significant differences were observed in levels of either soluble or total solid between BP juice and SP juice (Table 1). There was a significant difference in $\mathrm{pH}$, with SPjuice $(\mathrm{pH}=5.4)$ being more acidic than BPjuice ( $\mathrm{pH}=5.6)$. Likewise, density and viscosity also differed significantly (Table 1), with BP juice being denser and more viscous than SP juice. SP juice was lighter and greener than BP juice. Instrumentally, this was reflected by BP juice having a significantly lower $\mathrm{L}^{*}$, hue, and chroma than SP juice as seen in (Fig. 2).

A significant difference was observed between cichoric acid concentrations. The mean cichoric acid concentration measured in the SP juice $\left(0.85 \mathrm{mg} \cdot \mathrm{mL}^{-1}\right)$ was more than twice the concentration measured in the BP juice $(0.38$ $\left.\mathrm{mg} \cdot \mathrm{mL}^{-1}\right)$. This difference could be related to the significantly lower $\mathrm{pH}$ measured in the SP<smiles>C/C=C/C=C/CC/C=C/C=C/C(=O)CCC(C)C</smiles>

dodeca- 2E, 4E, 8Z, 19 E-tetraenotic acid isobutylamide<smiles>CC=CC=CCCC=CC=CC(=O)CCC(C)C</smiles>

dodeca- 2E, 4E, 8Z, 10 Z-tetraenoic acid isobutylamide

Fig. 1. Structures of the two major alkylamides found in aerial parts of E. purpurea: dodeca-2E,4E,8Z,10Etetraenoic acid isobutylamide and dodeca-2E,4E,8Z,10Z- tetraenoic acid isobutylamide.

Table 1. Measured physical parameters of E. purpurea juices obtained with a bag press (BP) or a screw press (SP).

\begin{tabular}{lccccc}
\hline Press & \multicolumn{5}{c}{ Parameters } \\
\cline { 2 - 6 } type & Soluble solids (\%) & Total solids (\%) & $\mathrm{pH}^{*}$ & Density* $\left(\mathrm{g} \cdot \mathrm{mL}^{-1}\right)$ & Viscosity* (cps) \\
\hline BP & 9.12 & 53.64 & 5.6 & 1.013 & 4.59 \\
SP & 9.37 & 53.73 & 5.4 & 1.008 & 4.26 \\
\hline
\end{tabular}

*Parameters showing statistically significant differences $(P<0.05)$ between press types as determined by two-group $t$ tests.

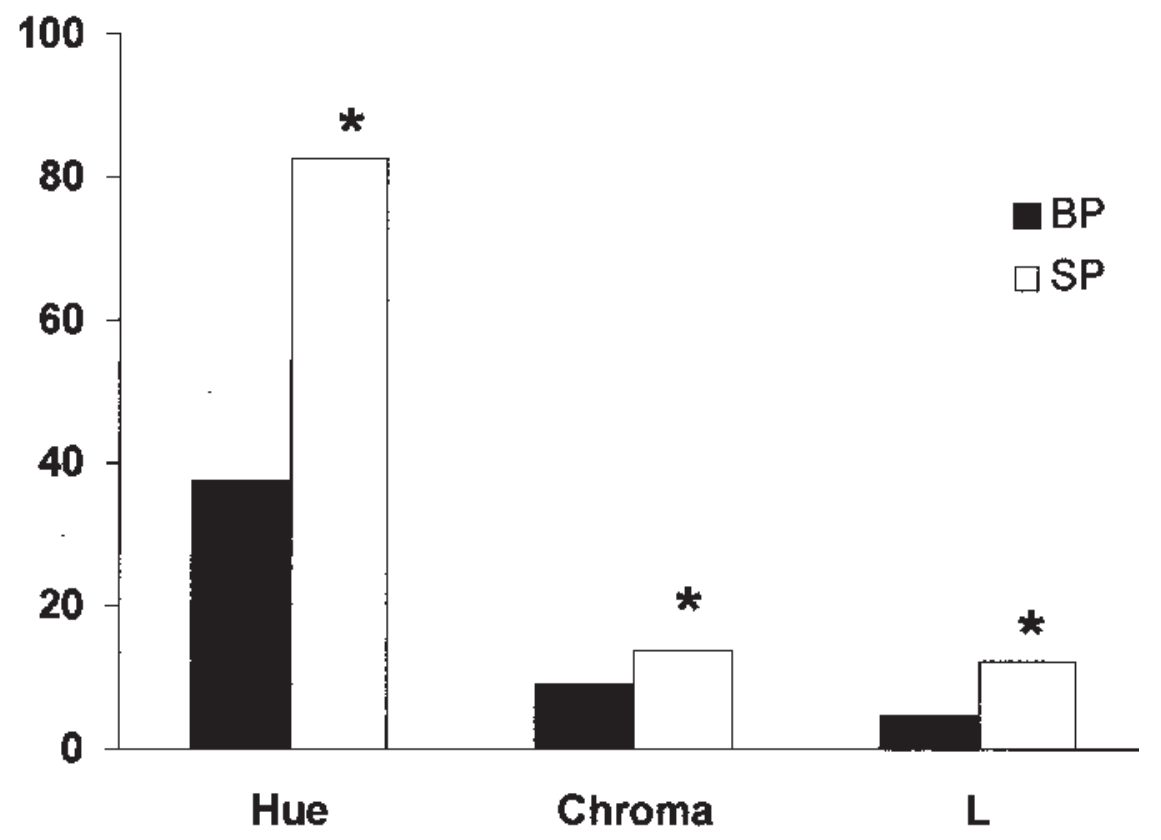

Fig. 2. Spectral reflectance profile of expressed E. purpurea juices from bag press (BP) and screw press (SP). *Significantly higher $(P=0.00)$ as determined by two-group $t$ test $(\mathrm{n}=24)$ between BP juice and SP juice. 


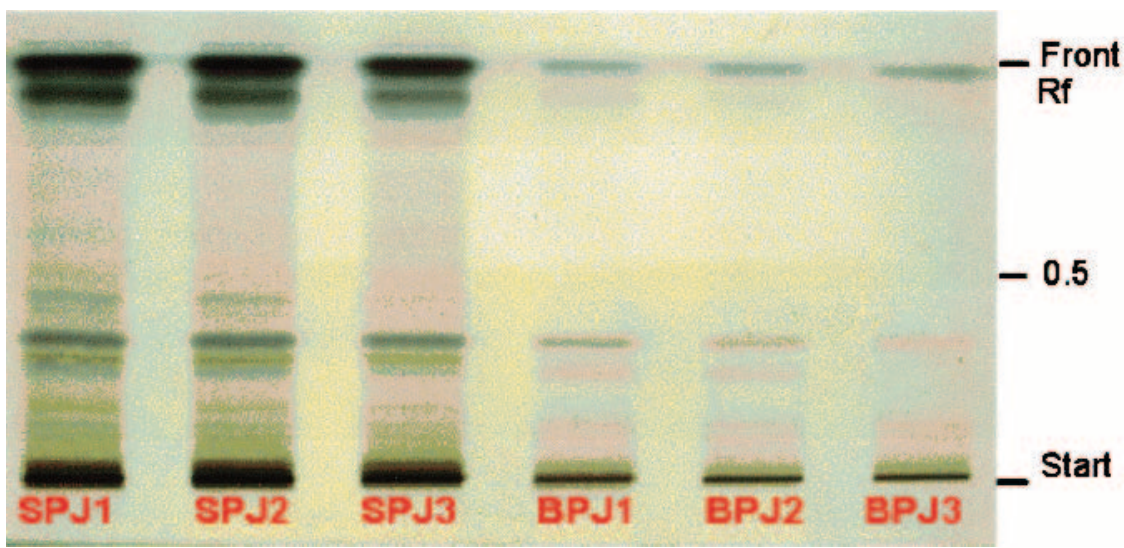

Fig. 3. TLC plates of $\mathrm{CHCl}_{3}$ extracted E. purpurea juices showing alkylamide profiles for three replicates of products from screw press (SPJ) and products from hydraulic bag-press (BPJ) using a 7 hexane : 3 ethyl acetate mobile phase. Alkylamides appear as purple.

from E. purpurea aerial parts or that the juice obtained from the SP is less susceptible to rapid degradation.

Despite that the feed : juice ratio is higher using the BPthan the SP(50\% vs. $34 \%)$, various engineering and processing efficiency considerations support the selection of SP over BPfor Echinacea juice expression. SP design is more suited for easy cleaning and sanitization. Thorough cleaning of every part of the SP is simple as the press can be completely disassembled. Conversely, the actual bag for the BP requires tedious and time-consuming manual cleaning in order to maintain efficiency. Additionally, SP is more versatile in that the rotational speed can be varied. This provides flexibility with regard to throughput and shear forces. Finally, SP is of a more robust design and our experience has shown that little maintenance is needed to assure its reliability. On the other hand, BP requires that the bag be occasionally replaced during use. These engineering considerations are often related to the peculiarities of the material being pressed and should be interpreted with respect to Echinacea herb.

We have observed differences in both chemical and physical properties of the juices expressed with the two different presses. However, the observation of greatest importance to the therapeutic value of the expressed Echinacea juice is that of the greater levels of cichoric acid and alkylamides, both of which are believed to contribute to the bioactivity of the plant. Therefore, based on these findings, SP appears to be a more suitable choice in the expression of $E$. purpurea aerial parts when compared to BP.

\section{Literature Cited}

Awang, D.V.C. 2000. The crisis of confidence in commercial herbal medicines. HerbWatch 2(1):1-3.

Bauer, R. 1998. The Echinacea story - The scientific development of an herbal immunostimulant. Proc. Soc. Econ. Bot. 317-332.

Bauer, R. 1999. Standardization of Echinacea purpurea expressed juice with reference to chicoric acid and alkamides. J. Herb. Spi. Med. Plant. 6(1):51-62.

Baugh, S. and S. Ignelzi. 2000. Hydrolysis and redox factors affecting analysis of common phenolic marker compounds in botanical extracts and finished products. J. AOAC Int. 83(5):1135-1140.

Brevoort, P. 1998. The booming US botanical market: A new overview. Herbalgram 44:33-48.

Cheminat, A., R. Zawatzky, H. Becker, and R. Brouillard. 1988. Caffeoyl conjugates from Echinacea species: Structures and biological activity. Phytochemistry $227: 2787-2794$.

Facino, R.M., M. Carini, G. Aldini, and C. Marinello.
1993. Direct characterization of caffeoyl esters with anthihyaluronidase activity in crude extracts from Echinacea angustifolia roots by fast atom bombardment tandem mass spectrometry. IL Farmaco 48:1447-1461.

Facino, R.M., M. Carini, G. Aldini, L. Saibene, P. Pietta, and P. Mauri. 1995. Echinacoside and caffeoyl conjugates protect collagen from free radical-induced degradation: A potential use of Echinacea extracts in the prevention of skin photo-damage. Planta Med. 61:510-514.

Hobbs, C. 1994. Echinacea: A literature review. Herbalgram 30:33-48.

Kim, H., T.D. Durance, C.H. Scaman, and D.D. Kitts. 2000. Retention of caffeic acid derivatives in dried Echinacea purpurea. J. Agr. Food Chem. 48:4182-4186.

Lin, Z., N. Neamati, H. Zhao, Y. Klryu, J.A. Turpin, C. Aberham, K. Strebel, K. Kohn, M. Witvrouw, C. Pannecouque, Z. Debyser, E. Clercq, W.G. Rice, Y. Pommier, and T.R. Burke, Jr. 1999. Chicoric acid analogues as HIV-1 integrase inhibitors. J. Med. Chem. 42:1401-1414.

Muller-Jakic, B., W. Brew, A. Pobstle, K. Redl, H. Greger, and R. Bauer. 1994. In vitro inhibition of cyclooxygenase and 5-lipoxygenase by alkylamides from Echinacea and Achillea species. Planta Med. 60(1):37-40.

Nüsslein, B., M. Kurmann, R. Bauer, and W. Kreis. 2000. Enzymatic degradation of cichoric acid in Echinacea purpurea preparations. J. Nat. Prod. 63:1615-1618.

Perry, N.B., J.W. van Klink, E.J. Burgess, and G.A. Parmenter. 1999. Alkamide levels in Echinacea purpurea: Effects of processing, drying and storage. Planta Med. 66:54-56

Proksch, A. and H. Wagner. 1987. Structural analysis of a 4-O-methylglucuronoarabinoxylan with immunostimulating activity from Echinacea purpurea. Phytochemistry 26(7):1989-1993.

Robinson, W.E., Jr., M.G. Reinecke, S. Abdel-Malek, Q. Jia, and A. Chow. 1996. Inhibitors of HIV-1 replication that inhibit HIV integrase. Proc. Natl. Acad. Sci. U.S.A. 93:6326-6331.

Roesler, J., C. Steinmuller, A. Kiderlen, A. Emmendorffer, H. Wagner, and M.L. Lohmann Matthes. 1991. Application of purified polysaccharides from cell cultures of the plant Echinacea purpurea to mice mediates protection against systemic infections with Listeria monocytogenes and Candida albicans. Intl. J. Immunopharm. 13(1):27-37.

Wagner, H. and S. Bladt. 1996. Plant drug analysis -A thin layer chromatography atlas. $2^{\text {nd }}$ ed. Springer-Verlag. Berlin. 